CARDIOVASCULAR MEDICINE

\title{
Hypoxaemia associated with an enlarged aortic root: a new syndrome?
}

\author{
J-C Eicher, P Bonniaud, N Baudouin, A Petit, G Bertaux, E Donal, J-F Piéchaud, \\ $M$ David, $P$ Louis, J-E Wolf
}

See end of article for authors' affiliations

.....................

Correspondence to: Dr Jean-Christophe Eicher, Centre de Cardiologie Clinique et Interventionnelle, Hôpital du Bocage, 2, Bd Maréchal de Lattre de Tassigny, 21034 Dijon Cedex, France; jean-christophe.eicher@ chu-dijon.fr

Accepted

29 November 2004

Published online first 10 March 2005

\begin{abstract}
Objective: To assess the mechanisms through which an enlarged aortic root may facilitate right to left shunting through a patent foramen ovale.

Patients: 19 patients with the platypnoea-orthodeoxia syndrome (POS) were compared with 30 control patients without platypnoea.

Interventions: Multiplane transoesophageal echocardiography.

Main outcome measures: The aortic root diameter, atrial septal dimension behind the aortic root, and amplitude of the phasic oscillation of the septum were measured. Four groups of patients were compared: 12 platypnoeic patients with a dilated aortic root (POS-D), 7 platypnoeic patients with a normal aortic root (POS-N), 15 control patients with a dilated aortic root (CONT-D), and 15 control patients with a normal aortic root (CONT-N).

Results: In POS-D and CONT-D patients, the apparent atrial septal dimension was $16.3(2.7) \mathrm{mm}$ and 17.4 (5.9) mm respectively, compared with 24.4 (5.2) $\mathrm{mm}$ in POS-N patients and 25 (4) mm in CONT-N $(p<0.005)$. Furthermore, the amplitude of septal oscillation was $14.7(2.5) \mathrm{mm}$ in the POS-D group versus $5.8(2.4) \mathrm{mm}$ in CONT-N ( $<<0.001$ ) compared with $23.3(3) \mathrm{mm}$ in seven patients with an atrial septal aneurysm $(p<0.001)$.

Conclusion: Patients with an enlarged aorta have an apparently smaller dimension and increased mobility of the atrial septum. These findings appear to result from compression by the aortic root and decreased septal tautness. Consequently, a "spinnaker effect" with the inferior vena caval flow may take place, opening the foramen ovale and leading to sustained right to left shunting.
\end{abstract}

A patent foramen ovale ( $\mathrm{PFO}$ ) is a defect in the atrial septum that results from incomplete fusion of the septum primum to the septum secundum. The persistence of a PFO into adulthood may lead to several complications, including paradoxical embolism of thrombus, air or tumoural material, and refractory hypoxaemia.

Normally, even if a potential channel between the atria remains, the higher left atrial pressure keeps the flap-like valve of the foramen ovale opposed to the septum secundum. Most cases of sustained right to left shunting through a PFO are seen in situations where right atrial pressure exceeds that of the left, forcing open the potentially patent foramen ovale.

However, right to left shunting can be less often observed in the absence of any demonstrable pressure gradient between right and left atria. Right to left shunting despite normal right atrial pressure has been reported after right pneumonectomy ${ }^{12}$ or in association with venous embryonic remnants. ${ }^{3}$ In these situations, an altered relation between the caval veins and the atrial septum presumably accounts for flow related rather than pressure related shunting.

A few cases of aneurysm of the ascending aorta associated with right to left shunting across a PFO have been reported, ${ }^{5-10}$ but evidence for a non-fortuitous association is still lacking. Therefore, we conducted a study to further analyse factors facilitating right to left shunting in patients with PFO, with particular attention paid to the potential interaction between an enlarged aortic root and the atrial septum.

\section{METHODS}

\section{Patients}

The study population consisted of 19 patients ( 13 men and six women, 42-78 years old) with identified interatrial right to left shunting despite normal right atrial pressure. The reason for hospital admission was the platypnoea-orthodeoxia syndrome (POS) or other types of postural dyspnoea in 16 patients. In the last three patients, the reason was recurrent cerebrovascular events in one patient, chest pain in a patient who had undergone a Bentall procedure for type A aortic dissection five years previously, and acute intramural haematoma of the descending aorta in a patient with coexistent aneurysm of the ascending aorta. These three patients did not have dyspnoea but were found to be cyanotic at examination. Cardiac catheterisation showed normal right sided pressures in all patients.

Two groups of patients without symptoms of POS served as controls: the CONT-D group comprised 15 patients who underwent transoesophageal echocardiography (TOE) for preoperative assessment of aortic valve disease and who were found to have a dilated aortic root; the CONT-N group was composed of 15 consecutive patients referred for TOE after a cerebrovascular event, in which the ascending aorta was found to be normal. No patient in the control groups had an atrial septal aneurysm (ASA).

\section{TOE and shunt diagnosis}

All the patients underwent multiplane TOE. Interatrial shunting was sought by injection of $10 \mathrm{ml}$ of contrast agent (Echovist, Schering AG, Berlin, Germany) into an antecubital vein in all patients and into the femoral vein in five patients. The patients were examined in the left lateral decubitus position. Three patients performed positional manoeuvres:

Abbreviations: ASA, atrial septal aneurysm; D, dilated aortic root; $N$, normal aortic root; PFO, patent foramen ovale; POS, platypnoeaorthodeoxia syndrome 


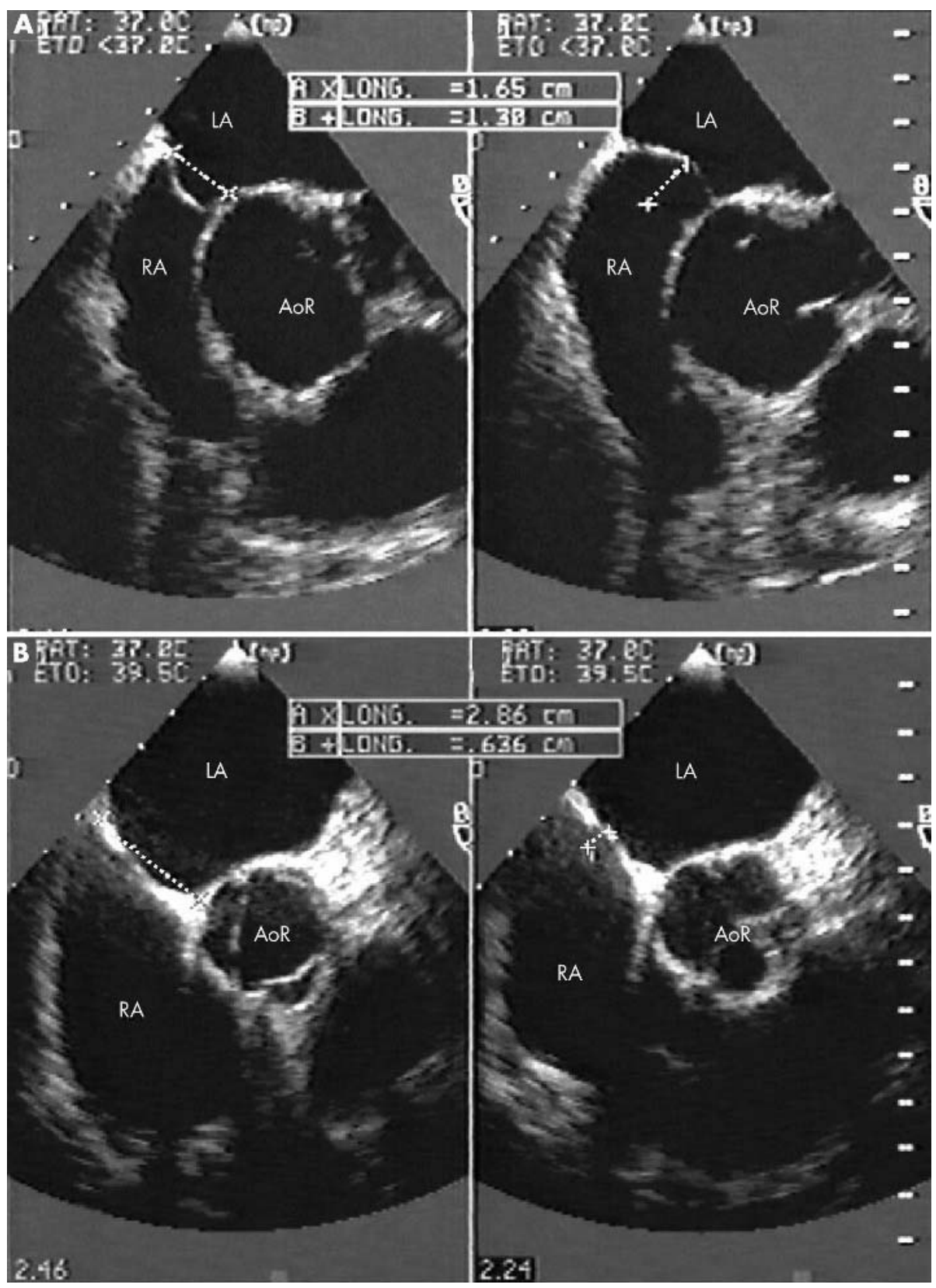

Figure 1 Transoesophageal echocardiographic measurements. (A) Patient with a dilated aortic root (AoR). (B) Patient with a normal AoR. LA, left atrium; RA, right atrium.

contrast infusion was repeated in the right lateral decubitus position in two patients who reported relief of dyspnoea in this position and in the upright position in a patient with platypnoea.

\section{Aortic measurements and atrial septum analysis}

The aortic root diameter was measured on TOE short and long axis views at the level of the sinuses of Valsalva as the largest transversal dimension. The upper normal limit of the aortic root diameter in adults is $40 \mathrm{~mm}$ in men and $36 \mathrm{~mm}$ in women. ${ }^{11}$ Patients with POS were divided into two subgroups according to these cut off values: the POS-D group patients had a dilated aorta; POS-N group patients had a normal aorta.

The apparent atrial septal dimension behind the aortic root was measured in an upper transoesophageal view at the level of the sinuses of Valsalva at an angle of $0-30^{\circ}$. In the same view, the oscillation amplitude of the atrial septum during normal breathing was determined as the distance between the maximum rightward and leftward positions of the fossa ovalis membrane (fig 1). An ASA was diagnosed whenever the membrane was found to bulge $>15 \mathrm{~mm}$ beyond the plane of the atrial septum at any moment of the cardiorespiratory cycle. ${ }^{12}$ We also sought the presence of a eustachian valve or a Chiari's network. We compared, firstly, the apparent atrial septal dimension in the four patient groups; and secondly, the oscillation amplitude of the atrial septum of POS-D patients without an ASA, POS patients with an ASA, and CONT patients.

\section{Statistical analysis}

All results are expressed as mean (SD). One way analysis of variance was used to compare echocardiographic data in the four groups. A Tukey test was performed if the analysis of variance showed significant differences. A probability value of $\mathrm{p}<0.05$ was considered significant. 


\begin{tabular}{|c|c|c|c|c|}
\hline Patient & $\begin{array}{l}\text { Aortic root } \\
\text { (mm) }\end{array}$ & Thoracic abnormalities & Other findings & Outcome \\
\hline $1^{*}$ & 47 & None & None & Death from stroke \\
\hline $2^{*}$ & 49 & None & None & Transcatheter closure \\
\hline $3^{*}$ & 51 & None & EV & Transcatheter closure \\
\hline $4^{*}$ & 45 & None & EV & Surgical closure \\
\hline $5^{*}$ & 43 & None & None & Treatment declined \\
\hline $6^{*}$ & 58 & None & None & Surgical closure + Bentall \\
\hline $7^{*}$ & 57 & None & None & Surgical closure + Bentall \\
\hline $8^{*}$ & 43 & None & EV & Transcatheter closure \\
\hline $9^{*}$ & 44 & Post-tuberculosis apical sequelae & None & Surgical closure \\
\hline $10^{*}$ & 47 & $\begin{array}{l}\text { Left phrenic elevation, } \\
\text { kyphoscoliosis }\end{array}$ & ASA & Transcatheter closure \\
\hline $11^{*}$ & 45 & $\begin{array}{l}\text { Right lung post-radiotherapy } \\
\text { lesions for cancer }\end{array}$ & None & Transcatheter closure \\
\hline $12^{*}$ & 43 & Right phrenic palsy & ASA & Transcatheter closure \\
\hline 13 & 38 & $\begin{array}{l}\text { Right haemothorax + left } \\
\text { pneumothorax }\end{array}$ & ASA/EV & Recovery \\
\hline 14 & 33 & Right pneumonectomy for cancer & ASA & Surgical closure \\
\hline 15 & 37 & $\begin{array}{l}\text { Right superior lobectomy/ } \\
\text { atelectasia of two lobes }\end{array}$ & ASA & Recovery \\
\hline 16 & 38 & Right pneumonectomy for cancer & $\mathrm{CN}$ & Transcatheter closure \\
\hline 17 & 35 & Post-sarcoidosis sequelae & $\mathrm{ASA} / \mathrm{CN}$ & Transcatheter closure \\
\hline 18 & 29 & None & "Low" PFO & Transcatheter closure \\
\hline 19 & 39 & None & ASA/EV & Surgical closure \\
\hline
\end{tabular}

\section{RESULTS}

Eighteen patients with POS were found to have a PFO and one patient had a small ostium secundum type of atrial septal defect. Among controls, five patients $(33 \%)$ in the CONT-N group, and four patients (26\%) in the CONT-D group had a PFO.

\section{Anatomical abnormalities associated with shunting among patients with POS}

Nine patients had thoracic or pulmonary abnormalities (table 1). Among them, four had an enlarged aortic root, one had a prominent eustachian valve, and two had a Chiari's network.

The aortic root was found to be dilated in 12 patients, particularly in eight patients with no thoracopulmonary abnormality. Three of them had a eustachian valve.

Two patients had neither pulmonary disease nor aortic root enlargement, but one of them had both an ASA and a prominent eustachian valve and in the other the PFO had an atypical, posteroinferior location, close to the opening of the inferior vena cava. Both patients had contrast injected through the femoral vein, showing much more intense shunting than from the antecubital approach.

\section{Morphology of the atrial septum}

The apparent atrial septal dimension, as measured behind the aortic root, was significantly smaller in POS-D and CONT-D patients than in patients with a normal aorta (table 2, fig 2).
We ascribed this finding to compression of the atrial septum by the inflated aortic root.

An ASA was found in five of the seven POS-N patients and in two patients of the POS-D group. Nevertheless, atrial septal movements in the 10 POS-D patients without an ASA appeared to be significantly greater than in CONT-N patients (14.7 (2.5) $\mathrm{mm} \quad v \quad 5.8$ (2.4) $\mathrm{mm}$ ), although remaining significantly less broad than in patients with a true ASA (23.3 (2.7) $\mathrm{mm}$ ) (fig 3). This finding was thought to be the result of a decreased tautness caused by the shifted aortic side of the septum. In the CONT-D group, atrial septal mobility was not significantly increased (6.4 (4.4) $\mathrm{mm}$ ) probably because of a higher left atrial pressure in these patients with valve disease, whose left ventricular end diastolic pressure was 18.5 (7.7) $\mathrm{mm} \mathrm{Hg}$.

\section{Patient outcome}

Among the patients with POS, one died of stroke caused by a paradoxical embolism (table 1). Two patients recovered from their symptoms, one after treatment of his atelectasia, the other one after healing of his traumatic lesions. One patient declined treatment for his PFO. Six patients underwent surgical closure and nine patients had transcatheter closure of the defect with immediate relief of their symptoms.

\section{DISCUSSION}

POS is a rare pattern of dyspnoea induced by upright posture (platypnoea), together with orthostatic cyanosis

Table 2 Clinical features and transoesophageal echocardiographic measurements in the four groups of patients

\begin{tabular}{lllll}
\hline & $\begin{array}{c}\text { POS-D } \\
(\mathbf{n}=12)\end{array}$ & $\begin{array}{c}\text { POS-N } \\
(\mathbf{n}=7)\end{array}$ & $\begin{array}{c}\text { CONT-D } \\
(\mathbf{n}=15)\end{array}$ & $\begin{array}{c}\text { CONT-N } \\
(\mathbf{n}=15)\end{array}$ \\
\hline Age (years) & $69.6(4.7)$ & $57.9(10.4)$ & $61.9(12.5)$ & $55.1(18.2)$ \\
Sex ratio & $8 \mathrm{M} / 4 \mathrm{~F}$ & $5 \mathrm{M} / 2 \mathrm{~F}$ & $12 \mathrm{M} / 3 \mathrm{~F}$ & $9 \mathrm{M} / 6 \mathrm{~F}$ \\
Aortic root diameter $(\mathrm{mm})$ & $47.7(5.2)^{*} \dagger$ & $35.6(3.5)$ & $50.3(5.3)^{*} \dagger$ & $31.3(2.7)$ \\
Atrial septal dimension $(\mathrm{mm})$ & $16.3(2.7)^{\star} \dagger$ & $24.4(5.2)$ & $17.4(5.9)^{*} \dagger$ & $25(4)$ \\
\hline
\end{tabular}

Data are mean (SD).

CONT, control patients; $\mathrm{D}$, dilated aortic root; $\mathrm{N}$, normal aortic root; POS, platypnoea-orthodeoxia syndrome. ${ }^{*} \mathrm{p}<0.005 \vee$ POS $-\mathrm{N}$. ** $\mathrm{p}<0.005 \vee$ CONT-N. 


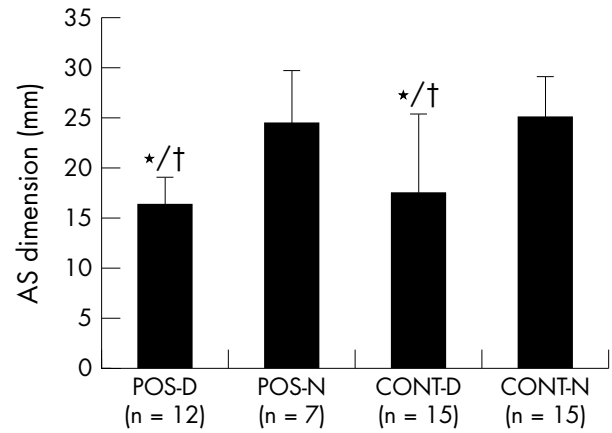

Figure 2 Apparent atrial septal (AS) dimension as measured behind the AoR in the four groups of patients. CONT, control patients; $D$, dilated aortic root; N, normal aortic root; POS, platypnoea-orthodeoxia syndrome. ${ }^{*} \mathrm{p}<0.05 v$ POS-N; $\uparrow \mathrm{p}<0.05 v$ CONT-N.

(orthodeoxia). It is usually associated with right to left shunting across the atrial septum despite normal right sided pressures and has been reported with various situations in which a preferential flow from the venae cavae towards the fossa ovalis develops. The precise mechanisms of shunting in the supine position are still poorly understood, but the distorted anatomical arrangement of the great veins relative to the atria is assumed to worsen in the upright position. Importantly, classic diagnostic investigation by contrast echocardiography may fail to show shunting if performed with the patient in the supine position: in some cases, the investigation should be repeated in the sitting position ${ }^{13}$ or in the upright position with the help of a tilt table. ${ }^{814}{ }^{15}$

Several anatomical reasons for flow related shunting can be invoked from both our study and the literature.

\section{Intracardiac, congenital contributing factors}

Four of our patients had a long eustachian valve and two of them had a Chiari's network, which are embryonic remnants of the right valve of the sinus venosus. This valve serves to direct the blood in embryonic life from the inferior vena cava through the fossa ovalis into the left atrium. If the entire valve persists, cor triatriatum dexter occurs, in which a spinnaker-like formation of the persistent venous valve is responsible for cyanosis occurring soon after birth. ${ }^{16}$ Normal absorption of the valve leaves rudiments which become eustachian and thebesian valves. Incomplete resorption with fenestrations results in a veil-like network, the Chiari's network. According to Schneider et $a l^{4}{ }^{4}$ this anomaly may favour persistence of PFO and the development of an ASA, and facilitate paradoxical embolism by directing blood flow from the inferior vena cava towards the region of the fossa ovalis. A similar flow pattern may be induced by a large eustachian valve as documented in a small number of reports of right to left shunting through either an atrial septal defect or a $\mathrm{PFO}^{5}{ }^{17}$; the flow pattern may also explain why femoral vein delivery of contrast medium may give much more demonstrative results than injections into cephalic veins. ${ }^{18}$

\section{Extracardiac contributing factors}

Some acquired anatomical alterations are likely to induce right to left shunting across a PFO. As seen in nine of our patients, the usual causes are thoracopulmonary deformities, mainly including right pneumonectomy, ${ }^{14}{ }^{15}$ but also lobectomy, localised bullous emphysema, ${ }^{13}$ kyphoscoliosis, and phrenic palsy. In these situations, the arrangement between the heart and the caval veins is distorted. For example, Mercho et $a l^{2}$ reported a magnetic resonance imaging study showing a right atrium abnormally inferior to the left atrium and the plane of the interatrial septum atypically horizontal,

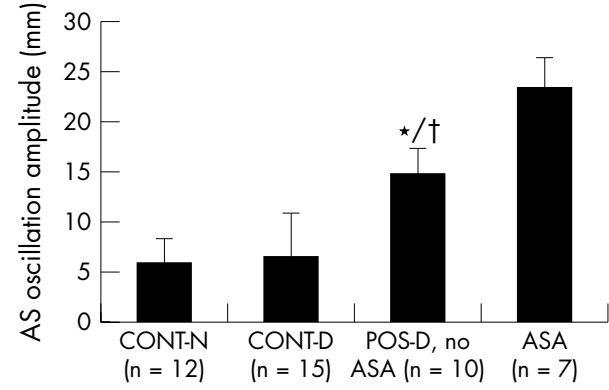

Figure 3 AS oscillation amplitude in patients in the CONT-N, CONT-D, and POS-D groups without an atrial septal aneurysm (ASA) and with an ASA. ${ }^{*} p<0.005 v$ controls; $\uparrow p<0.005 v$ ASA.

causing it to overlie the opening of the inferior vena cava and facilitating direct streaming through the defect. Those authors also speculated that the weight of the heart in the shifted position pulled downwards on the interatrial septum, causing the foramen ovale to open or to widen in the upright position.

\section{Role of the thoracic aorta}

The finding that $63 \%$ of our patients with POS also had an enlarged aortic root is striking. Eight cases (table 3) of platypnoea associated with an enlarged aortic root have been reported in the literature ${ }^{5-10}$ but no documented pathophysiological explanation has been proposed. In the case reported by Thomas et al, ${ }^{5}$ severe right to left shunting through a widely patent foramen ovale was mainly related to a large eustachian valve and a redundant septum secundum that billowed outwards into the right atrium; nevertheless, an enlarged aortic root, compressing and distorting the right atrium, was also reported, together with a severe kyphosis. Dear et $l^{6}$ reported similar symptoms in a 68 year old woman with both kyphosis and a dilated ascending aorta, but the possibility of a pathophysiological link was not raised. Two cases of elderly women with large ascending aortic aneurysms and desaturation were described by Savage et al, ${ }^{7}$ who suggested two contributing mechanisms: firstly, compression of the right atrium by the aneurysm causing an increase in right atrial pressure; and secondly, deformation of the right atrium causing preferential flow of blood from the inferior vena cava towards and through the foramen ovale. Popp et al ${ }^{8}$ reported the case of an 80 year old woman with POS associated with an ectatic and elongated ascending aorta; compression of the right atrium in the upright position by the enlarged aorta was proposed, but the patient also had moderate kyphoscoliosis and became dyspnoeic after a thoracic spine compression fracture. The two patients reported by Laybourn et al had platypnoea and orthodeoxia associated with an ascending aortic aneurysm; those authors suggested that enlargement of the ascending aorta induced a counterclockwise rotation of the heart, thereby distorting the position of the atrial septum relative to caval inflow. Finally, Kubler et al $^{10}$ reported one case among three POS being associated with an aneurysm of the ascending aorta. In our series of 12 patients with an enlarged aortic root, a stereotypical pattern of billowing, though non-aneurysmal, septa was observed, which has not been reported so far.

\section{Relevance of increased septal mobility}

Anatomically, when viewed from the right atrium, the morphology of the fossa ovalis region is usually marked by a smooth ridge caused by the limbus of the fossa; the septum in the fossa is made of the taut septum primum, which closes the foramen ovale. ${ }^{19}$ In case of an ASA, the septum primum is severely redundant and bulges far into the right or left atrial 
Table 3 Main features of the eight reported cases of intra-atrial right to left shunting associated with an enlarged aortic root

\begin{tabular}{|c|c|c|c|c|c|}
\hline Author, year & Sex & $\begin{array}{l}\text { Age } \\
\text { (years) }\end{array}$ & Atrial septum & Other findings & $\begin{array}{l}\text { Aortic diameter } \\
(\mathrm{mm})\end{array}$ \\
\hline Thomas, $1987^{5}$ & $\mathrm{~F}$ & 74 & $\begin{array}{l}\text { Redundant ASD } \\
15 \mathrm{~mm}\end{array}$ & EV, severe kyphosis & NA \\
\hline Dear, $1995^{6}$ & $F$ & 68 & PFO 10 mm & Kyphosis & 50 \\
\hline Savage, $1996^{7}$ & $\mathrm{~F}$ & 82 & PFO & None & 78 \\
\hline Savage, $1996^{7}$ & $\mathrm{~F}$ & 74 & PFO & None & 86 \\
\hline Laybourn, $1997^{9}$ & $M$ & 54 & PFO & None & 60 \\
\hline Laybourn, $1997^{9}$ & $\mathrm{~F}$ & 86 & PFO & None & 76 \\
\hline Popp, $1997^{8}$ & $\mathrm{~F}$ & 80 & PFO & $\begin{array}{l}\text { Kyphoscoliosis, new thoracic } \\
\text { spine compression fracture }\end{array}$ & NA \\
\hline Kubler, $2000^{10}$ & $\mathrm{~F}$ & 72 & PFO $20 \mathrm{~mm}$ & None & 50 \\
\hline
\end{tabular}

cavity. Another normal pattern, the so called floppy atrial septum, should not be mistaken for an ASA: in this instance, the septum of the fossa is slightly redundant and more mobile but cannot be pushed far towards the centre of either atrial cavity. ${ }^{19}$ PFO is a common associated finding in both ASA and floppy septum; it is noteworthy that if the PFO is a true valvar PFO then the shunting is usually observed only when the flap valve intermittently lifts into the left atrium and opens the left mouth of the oblique channel. Mobility of the membrane is probably an important factor that increases the likelihood of shunting; this theory is supported by the finding that type IA ASAs, which bulge continuously into the right atrium without phasic oscillation, are not associated with shunting. ${ }^{20}$ In our patients with both a dilated aortic root and POS, we saw a pattern resembling a floppy atrial septum, with the difference that the septum did not seem redundant but rather was pushed laterally by the sinuses of Valsalva.

\section{Synthetic pathophysiological hypothesis}

We believe that an enlarged or horizontalised aortic root may interfere with the atrial septum and contribute to the interception of inferior vena caval flow through several potential mechanisms. Firstly, a rightwards shift of the fossa ovalis, together with a narrowing of the angle between atrial septum and inferior vena cava, brings the venous blood flow and the defect into a closer relation (fig 4). Secondly, the bulging of the aortic root above the tricuspid orifice, sometimes completed by the presence of a eustachian valve, may behave functionally like an "acquired cor triatriatum dexter". Thirdly, as our TOE findings showed, the enlarged aortic root reduces the distance between the aorta and the atrial posterior wall, thus loosening the tautness of the atrial septum: this allows the flap valve of the fossa ovalis to move more freely (provided that the left atrial pressure is normal), somewhat in the manner of an ASA. Thus, the flap valve may undergo a spinnaker effect with the venous flow and a billowing to the left that maintains the foramen ovale wide open (fig 4). Lastly, and more hypothetically, right atrial compliance may be reduced owing to smaller size induced by compression by the aortic root.

Therefore, the reasons why patients with a congenital defect develop symptoms late in adult life (mean age 72.4 years among the eight patients in the literature, 69.7 years in our series) appear obvious. Aortic root dilatation is a progressive and age dependent process. Furthermore, in some instances, the development of osteoporosis related kyphosis may play a part by progressively making the ascending aorta and atrial septum more horizontal. These alterations will finally result in a syndrome that may be likened to a late return to fetal circulation.

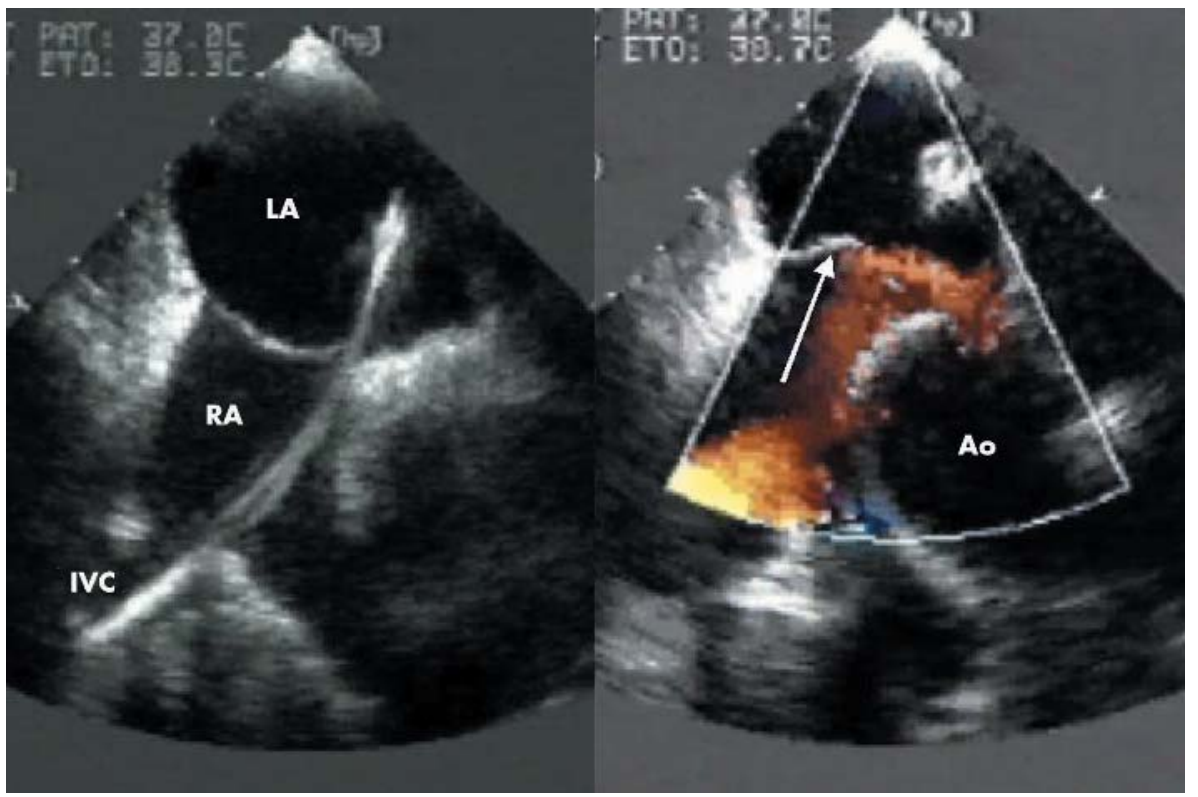

Figure 4 Transoesophageal echocardiography during a transcatheter closure procedure in a patient with a dilated AoR. Patent foramen ovale opens exactly opposite the inferior vena cava (IVC), as shown by the guidewire coming from the vein and crossing the defect directly (left). Colour Doppler imaging shows that flow coming from the IVC is perpendicular to the atrial septal plane (arrow) and lifts the flap valve of the fossa ovalis intermittently, promoting right to left shunting (right). The bulging AoR probably also contributes to drive flow against the septum. Ao, aorta. 


\section{Conclusion}

An enlarged aortic root is not an uncommon finding among patients with platypnoea-orthodeoxia. Even when mild to moderate, such an enlargement seems able to alter atrial septal geometry, as shown by TOE findings. Although often seen together with other contributing factors, aortic root dilatation may be a risk factor for shunting when associated with an atrial septal defect or a PFO.

\section{Authors' affiliations}

J C Eicher, A Petit, G Bertaux, P Louis, J E Wolf, Department of Cardiology, Centre Hospitalo-Universitaire, Dijon, France

P Bonniaud, N Baudouin, Department of Pneumology, Centre HospitaloUniversitaire, Dijon, France

E Donal, Department of Cardiology, Centre Hospitalo-Universitaire, Poitiers, France

J F Piéchaud, Jacques Cartier Institute, Massy, France

M David, Department of Cardiovascular Surgery, Centre HospitaloUniversitaire, Dijon, France

\section{REFERENCES}

1 Schnabel TG, Ratto O, Kirby CK, et al. Postural cyanosis and angina pectoris following pneumonectomy: relief by closure of an interatrial septal defect. J Thorac Surg 1956;32:246-50.

2 Mercho N, Stoller JK, White RD, et al. Right-to-left interatrial shunt causing platypnea after pneumonectomy. Chest 1994;105:931-3.

3 Strunk BL, Cheitlin MD, Stulbarg MS, et al. Right-to-left interatrial shunting through a patent foramen ovale despite normal intracardiac pressures. Am J Cardiol 1987:60:413-5.

4 Schneider B, Hofmann T, Justen MH, et al. Chiari's network: normal anatomic variant or risk factor for arterial embolic events? J Am Coll Cardiol 1995;26:203-10

5 Thomas JD, Tabakin BS, Ittleman FP. Atrial septal defect with right to left shunt despite normal pulmonary artery pressure. J Am Coll Cardiol 1987;9:221-4.
6 Dear WE, Chen P, Barasch E, et al. Sixty-eight-year-old woman with intermittent hypoxemia. Circulation 1995;91:2284-9.

7 Savage EB, Benckart DH, Donahue BC, et al. Intermittent hypoxia due to right atrial compression by an ascending aortic aneurysm. Ann Thorac Surg 1996:62:582-3.

8 Popp G, Melek H, Garnett AR. Platypnea-orthodeoxia related to aortic elongation. Chest 1997; 112:1682-4.

9 Laybourn KA, Martin ET, Cooper RA, et al. Platypnea and orthodeoxia: shunting associated with an aortic aneurysm. J Thorac Cardiovasc Surg 1997; 113:955-6.

10 Kubler P, Gibbs H, Garrahy P. Platypnoea-orthodeoxia syndrome. Heart 2000:83:221-3.

11 Roman MJ, Devereux RB, Kramer-Fox R, et al. Two-dimensional echocardiographic aortic root dimensions in normal children and adults. Am J Cardiol 1989;64:507-12.

12 Hanley PC, Jamil Taijk A, Hynes JK, et al. Diagnosis and classification of atrial septal aneurysm by two-dimensional echocardiography: report of 80 consecutive cases. J Am Coll Cardiol 1985;6:1370-82.

13 Al Khouzaie T, Busser JR. A rare cause of dyspnea and arterial hypoxemia Chest 1997;112:1681-2

14 Seward JB, Hayes DL, Smith HC, et al. Platypnea-orthodeoxia: clinical profile, diagnostic workup, management, and report of seven cases. Mayo Clin Proc 1984;59:221-31.

15 Herregods MC, Timmermans C, Frans E, et al. Diagnostic value of transesophageal echocardiography in platypnea. J Am Soc Echocardiogr 1993;6:624-7.

16 Trento A, Zuberbuhler JR, Anderson RH, et al. Divided right atrium (prominence of the eustachian and thebesian valves). J Thorac Cardiovasc Surg 1988:96:457-63.

17 Gallaher ME, Sperling DR, Gwinn JL, et al. Functional drainage of the inferior vena cava into the left atrium: three cases. Am J Cardiol $1963 ; 12: 561-6$

18 Gin KG, Huckell VF, Pollick C. Femoral vein delivery of contrast medium enhances transthoracic echocardiographic detection of patent foramen ovale. J Am Coll Cardiol 1993;22:1994-2000.

19 Silver MD, Dorsey JS. Aneurysms of the septum primum in adults. Arch Pathol Lab Med 1978;102:62-5.

20 Pearson AC, Nagelhout D, Castello R, et al. Atrial septal aneurysm and stroke: a transesophageal echocardiographic study. J Am Coll Cardiol $1991 ; 18: 1223-9$

\section{IMAGES IN CARDOLOGY}

\section{Tricuspid aortic valve aneurysm}

A 49 year old man presented through accident and emergency with an acute confusional state and a five day history of being nonspecifically unwell. On examination he was found to be pyrexial $\left(38.4{ }^{\circ} \mathrm{C}\right)$ and there was systolic murmur. Magnetic resonance imaging (MRI) of the brain was suggestive of meningoencephalitis and it was treated accordingly. Blood cultures revealed growth of Staphylococcus aureus and echocardiography studies were requested to rule out infective endocarditis. Transthoracic echocardiography demonstrated a structure arising from the non-coronary cusp of the aortic valve. It was protruding into the left ventricular outflow tract. Interestingly, there was evidence of blood flow inside the structure, proving that it was not a solid lesion and suggesting that it may well be a localised aneurysmal formation. The patient underwent transoesophageal echocardiography in order to clarify anatomy of the abnormality. It clearly demonstrated flow into the structure and into the left ventricular outflow tract (panels A-C), confirming a localised aneurysmal or sac-like nature of it.
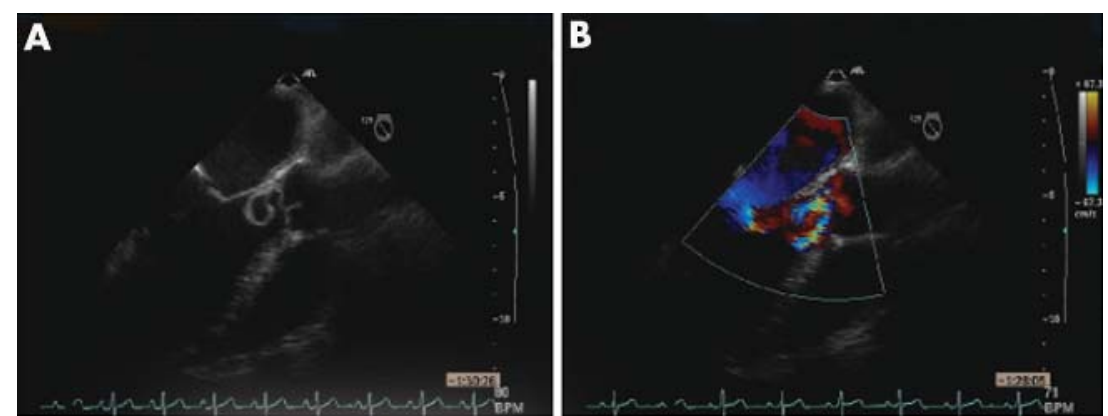

MRI failed to provide additional information. The patient became asymptomatic within a few days of antibiotic treatment with rapid normalisation of inflammatory markers. The patient was discharged home with advice regarding antibiotic prophylaxis for infective endocarditis. We concluded that the structure was most likely a congenital abnormality. To date we have found no reports in the literature of a similar abnormality in a tricuspid aortic valve. A case has been reported of aneurysmal formation of a bicuspid aortic valve (Ratib et al. Circulation 2004;109:671). doi: 10.1136/hrt.2004.056796

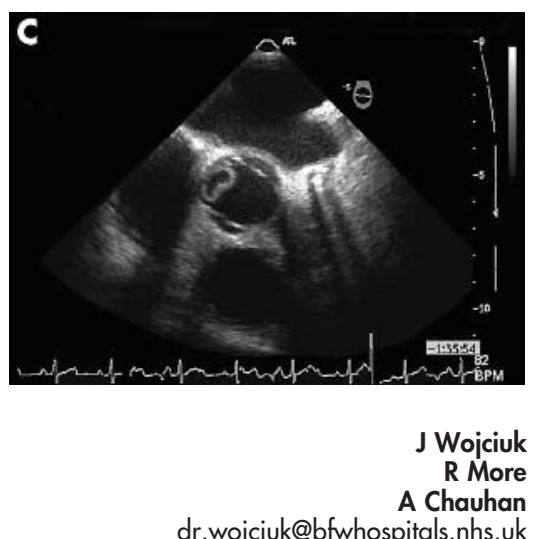

